\title{
THE METABOLIC RESPONSE TO SURGERY
}

\author{
By H. A. F. Dudley, F.R.C.S.E. \\ Department of Clinical Surgery, University of Edinburgh
}

The metabolic response to surgery includes by definition all the alterations in cellular and extracellular activity that follow injury or operation, but in common use the term is confined to the changes in utilization and exchange of the substances principally involved, that is, water, sodium, potassium and nitrogen.

Metabolic events may be studied in two ways: first, by direct observation of chemical or physicochemical changes in individual tissues or in the body as a whole, a method not often applicable to man except to measure changes in the plasma concentrations; secondly, by computing a 'balance' from the measurement of the rates of intake and output. Changes in such an 'external' balance give some indication of rates of utilization and of the increase or decrease of total body stores, but these studies have many shortcomings both in execution and in interpretation. They do not give any information about either intermediate biochemical events or the origin of the end products that are excreted. The construction of a balance by direct addition and subtraction may well be unjustified, particularly in the case of nitrogen which is assimilated in a completely different form from that in which it is excreted. Difficulties also arise in computing both intake and output: for example, some authors have regarded the nitrogen, sodium and potassium of administered whole blood as an increment on the intake side (Flear and Clarke, 1955) in spite of the known very slow utilization of plasma proteins and of the nitrogen of red cells. Further, although loss of whole protein from a raw surface is undoubtedly a debit on the body stores, it may have a different metabolic effect from nitrogen excreted in the urine predominantly as urea. Finally, the accuracy of balance studies is low so that changes of less than 15 per cent. are always of doubtful significance (Reiss et al., 1956).

In assessing the significance of metabolic changes after injury, a distinction must always be made between the metabolic events that follow a single stimulus such as a surgical cperation and those which take place in the presence of continued stress, for example after a burn or in a patient with peritonitis. Particularly in the latter instance $\vec{\circ}$ gross changes in the external balance may occur $\vec{\omega}$ not only because of metabolic events but also as a $\stackrel{\circ}{\circ}$ result of treatment with fluid and electrolytes, 8 and balance figures must consequently be inter- 3 . preted with great caution. This matter is of more than theoretical interest because it has resulted in $\omega$ much confusion of thought. Renal activity is greatly altered after injury; if in spite of limitation $\cup_{\infty}$

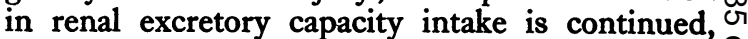
' retention' may result. However, the increase $\stackrel{\circ}{?}$ in body content of the substance concerned is a secondary phenomenon and not a true metabolic $\overparen{D}$ event. The use of the term ' retention' should be $\overparen{\varnothing}$ abandoned in descriptions of normal metabolism after injury. A similar argument applies to ' loss,' the use of which should be confined $\overrightarrow{0}$ conditions in which it is clearly shown that the body's stores are reduced and that the levels of th renal or extrarenal rate of excretion are largely independent of intake.

\section{Water}

The volume of water in the body is kept within narrow limits by the osmotic control exercised by $\overrightarrow{\overrightarrow{0}}$ the hypothalamic osmoreceptors and the posterior 3 pituitary gland (Verney, 1947). A decrease in total body water provides an osmotic stimulus to increase the rate of secretion of antidiuretic $\overline{ }$ hormone; renal tubular reabsorption of water 3 becomes more complete, and the output of urine falls. Increase in total body water normally produces the reverse effects, but for about 48 욱 hours after injury this response is suppressed. The volume of the urine is small and its concentra- $\frac{\text { ㅇ }}{9}$ tion high so that in the first 24 hours only 500 to $D$ $600 \mathrm{ml}$. of highly concentrated urine, with a specific gravity of at least 1.030 and an osmolarity of $1,000 \mathrm{~N}$ milliosmols/litre or more, may be excreted. This corresponds to the 'volume obligatoire' of water $N$ deprivation (McCance and Young, 1944; Gamble, $\omega$ 1954) and, as in this condition, the exact volume and concentration found are dependent upon the 0 amounts of solutes which must be excreted. Similarly after injury the urinary output can be $\stackrel{\text { ? }}{+}$ markedly increased only by augmenting the solute $\frac{T}{0}$ 
load (Dudley et al., I957). Although direct measurements of increased antidiuretic activity in the blood after injury have not proved possible, the levels of antidiuretic substances in urine after operation are known to be increased (Cline et al., 1953; Lewis, 1953), and, as LeQuesne and Lewis (1953) have emphasised, it is difficult to conceive of any physiological mechanism other than a prolonged intense secretion of pituitary antidiuretic hormone which will explain the highly concentrated urine and the absence of response to water loading (Dudley et al., 1954). This latter phenomenon is not related to the concomitant level of sodium excretion; the loss of renal excretory capacity in the first 24 to 36 hours is for water alone and water diuresis has usually been restored to normal before sodium excretion has reached a minimum.

\section{Sodium and Potassium}

In the first three days after injury sodium excretion decreases progressively in a manner similar to that seen after withdrawal of sodium from the diet (Wilkinson et al., 1949). Renal conservation is usually incomplete but if the stress is prolonged the levels of sodium in the urine are markedly reduced so that only about $10 \mathrm{mEq}$. are excreted daily. Unlike conservation caused by decreased intake, the output of sodium after injury cannot be greatly increased by the administration of sodium, and the addition of sodium to the body in amounts greater than can be excreted will result in its accumulation in the extracellular fluid. The excessive post-operative administration of ' physiological 'saline may easily produce oedema.

The absolute excretion rate of potassium is markedly increased in patients who undergo major surgical operations (Blixenkrone-Moller, I949; Randall et al., r949; Wilkinson et al., 1950; Wilkinson, r956) and the rate of loss increases with the magnitude of the injury. Some of the potassium is excreted as a result of the mobilization of intracellular protein but some is selectively withdrawn from the matrix of the cell. The increased excretion is usually short-lived and except in instances where there is a prolonged phase of tissue breakdown, as in burns or after injury to bones (Cuthbertson, I939), potassium excretion returns to normal or subnormal levels on the second or third day after injury. Unlike renal sodium loss which is self-limiting, potassium loss continues in the absence of intake so that if a return to a normal diet is delayed potassium depletion may gradually develop. However, this is not a metabolic consequence of the large losses immediately after injury but is a result of continued seepage of potassium from the body over a period of at least ten days.

\section{Nitrogen}

In his pioneer work Cuthbertson (1929, I 30 . 1932, I936) clearly demonstrated that urigary nitrogen excretion rates were increased after injury even if nitrogen and calorie intakes were maintained. The rise in rate of excretion was sufficent to cause a negative ' balance' which implied? breakdown of lean tissue. Cuthbertson's ${ }_{\bar{G}}$ vestigations were made on fractures in which nitrogen loss is more prolonged than in any other circumstances, but similar changes have since described in a large number of studies on other types of injury (see Moore and Ball, I952, For review). In most instances, particularly after gastro-intestinal operations, a considerable compibution is made to the negativity of the balanceby the starvation which is inseparable from the operative procedure and often the increasewin absolute nitrogen excretion rate is slight ghd transient. The response is more marked. ${ }_{i n}$ healthy subjects undergoing major operations \&్d is minimal or absent if a second injury is infligfed after a short interval (Hardy and Cole, I953). Loss of nitrogen in man is larger and more prolonged when calorie intake is inadequate, कout paradoxically in undernourished debilitaged patients there may be a so-called 'depetem response' (Moore and Ball, r952) characterised by a minimal increase in nitrogen excretion. OT situation may have its experimental counterciart in the recent demonstration that the norma fise in post-operative nitrogen excretion does not ake place under the somewhat artificial circumstanes of a protein-free diet (Campbell et al., I957).

Why large quantities of protein from undamased tissues should normally be catabolized and excreged is not clear. Two possibilities exist: first, protein breakdown is increased in order to supply. energy; secondly, that catabolism is necessary for the repair process. Probably both factors are involved; the reduction of nitrogen loss associated with an adequate calorie intake after injü! (Abbott et al., 1954; Sutherland, 1954) suggests that proteins are utilized for energy processios; the peak of nitrogen loss at the third to fourth 94 ! when repair is getting under way and the continused negative balance when the repair process is piplonged are indirect evidence that the excretionof nitrogen is correlated with the repair of tissues.

\section{Other Changes}

The excretion rates of phosphorus, sulphwir (Cuthbertson, 1929) and magnesium (Reiss et I956) are all increased after injury similarly ક્o those of potassium and nitrogen and have probaly. the same significance. The glucose tolerafece curve approximates that of the diabetic (Howard, 1955), an observation which suggests that afष्षr 
injury utilization of carbohydrate is altered. There is also a considerable oxidation of fat after severe injury (Moore and Ball, 1952) and this is possibly correlated with the change in carbohydrate metabolism.

Slight, but only slight, changes occur in the serum electrolyte levels. After major surgery and in the absence of water or saline overloading, there is a transient fall in serum sodium concentration with either a maintained or slightly increased level of serum potassium (Wilkinson et al., 195I). These changes are exaggerated in seriously ill patients (Wilson et al., 1954) who may, however, have stores of sodium and potassium in the body which are altered in the reverse direction from the serum concentrations. Such paradoxical electrolyte levels are occasionally the result of adrenal insufficiency but more commonly are caused by a basic disturbance of function at the cell membrane. The determination of the serum electrolyte concentrations is not usually helpful in the management of patients after injury or operation except in the special cir'cumstances of water intoxication or of anuria, and in particular the detection of hyponatraemia should not lead to indiscriminate administration of sodium (Moore, r954; Elkinton, 1956).

\section{Causation}

The pathways involved in the metabolic events which occur after injury are far from clear. That diminished renal excretion of water is almost certainly a function of increased posterior pituitary activity has already been mentioned. The stimulus for the non-osmotic secretion of antidiuretic hormone is presumably pain, but the duration of post-operative antidiuresis is unique. The changes in sodium, potassium and nitrogen excretion might be produced by an overall increase in activity of the adrenal cortex, as was first suggested by Albright (1942): not only is it possible to bring about similar metabolic events by the administration of adrenocortical hormones (Moore and Ball, 1952), but also after injury and after operation active adrenocortical steroids of the 17 hydroxy-group are present in increased concentrations in the blood and are excreted in large quantities in the urine (Moore and Ball, 1952; Hardy, 1954; Sandberg et al., 1954; Moore et al., 1955; Steenburg et al., 1956). The presence of adrenocortical hormones is necessary for survival after injury, and in adrenalectomized or hypophysectomized individuals the normal maintenance dose of cortisone or one of its analogues must be increased if operation is undertaken. Nevertheless, the normal metabolic sequence of events occurs after adrenalectomy or hypophysectomy in a patient maintained on a constant dose of cortisone (Mason, 1955; Robson et al., 1955; Jepson et al., 1957). Thus adrenocortical hormones may merely be ' permissive' to the metabolic events (Ingle, I952); alternatively, the peripheral levels of these hormones may be increased by changes in renal elimination or in hepatic inactivation with consequent enhanced effects (Steenburg and Ganong, 1955; Robson et al., 1956). Finally, the measurable changes in adrenocortical activity are usually over long before the metabolic course has been completed. Thus the nature of adrenocortical participation in the metabolic response to injury is as yet unsettled, and it is becoming apparent that the injured tissue itself or perhaps the continued stimulus of the repair process may be of importance in initiating and maintaining metabolic events.

The individual adrenocortical hormones involved in the metabolic response that follows injury are not known but the acute changes in potassium and sodium excretion after injury could well be caused by changes in secretion of aldosterone; the demonstration of increased amounts of a substance that resembles this hormone in the urine after injury lends support to this hypothesis (Llaurado, 1956).

The initiation of adrenocortical activity presumably rests in the pituitary; numerous experiments both by Hume (1953) and by Harris (1955) have yielded much evidence to suggest that the anterior hypophysis is under the neuro-humoral control of the hypothalamus and that activity in this centre stimulates the production of ACTH. The stimuli responsible for hypothalamic activity remain undetermined; changes in extracellular and intravascular volume are known to set in train the sequence of events which produces alterations in the rate of secretion of aldosterone (Barrter, 1956), and Flear and Clarke (1955) have suggested that a reduction in blood volume might initiate most of the metabolic changes which are observed after injury. Much further work is required to elucidate these problems.

\section{Clinical Correlations}

The most important lesson to be learnt from the present knowledge of the metabolic response to surgery is the avoidance of unnecessary therapy. The teleological interpretation of the changes in electrolyte and nitrogen excretion is that on the one hand they conserve total body water and extracellular volume, and that on the other hand they establish the conditions for the formation of the inflammatory exudate and the initiation of the processes of repair. The surgeon must not hinder these adjustments by the administration of excessive amounts of water or of sodium and water which the body does not need and cannot excrete, 
and the administration of potassium soon after an uncomplicated injury is also unnecessary (Wilkinson, 1956). In the first 48 hours quantitative losses of these substances are insufficient to affect the bodily functions except under two circumstances: first, when additional extrarenal losses are encountered, and secondly, when a return to a normal water and electrolyte balance by the ingestion of a good mixed diet is delayed. Fluid and electrolyte imbalance after injury is postponed or avoided if attention is devoted to these principles, and if extrarenal losses are limited as far as possible and are replaced qualitatively and quantitatively. In the management of general surgical cases one of the most important measures which reduces extrarenal losses is the prohibition of unlimited drinking of water when a nasogastric tube is in position. If free drinking is allowed, not only is the computation of a fluid balance chart difficult but also the output from the stomach is greatly increased.

The quantitative significance of the increased excretion of nitrogen and of the consumption of fat after a single injury such as a major operation is small. The nitrogen losses are not greatly in excess of those seen in starvation, although fat is probably broken down at about five times the normal rate so that a slight loss of weight (up to $3 \mathrm{~kg}$. in five days) is a normal result of any major injury. Attempts to 'convert' a negative to a positive balance by the administration of protein by mouth or by vein are only partly successful, and are based on a misconception of the nature of the catabolic phase. The situation is quite different in conditions of continuing stress such as burns or multiple injuries. In such cases there is a persistent long-term drain on the stores of nitrogen, potassium and fat, and unless these are supplied in additional quantities, preferably by mouth, serious deficits will rapidly result. In judging the nature of a patient's progress there is no more reliable guide than his weight (Moore, 1955), and a scale capable of weighing the bedfast patient is an essential item of equipment in every surgical unit.

Finally, the 'depletion response' does not necessarily prejudice the chance of survival but undernourished patients and those with paradoxical electrolyte levels are more prone to postoperative complications and definitive operations should be postponed if possible until nutrition is improved.

\section{Conclusions}

The saying that every operation is a physiological experiment is true both in its original meaning of the function of organs and in its new interpretation of post-operative biochemical change. In the vast majority of patients then necessary adjustments are made automatically? and without the need for any action by the surgeon $\mathbb{}$ Nevertheless, if errors of commission and omission are to be avoided in the management of the oc casional complicated case, the operator must haves some knowledge of the biochemical cornerstonesp of convalescence.

\section{BIBLIOGRAPHY}

ABBOTT, W. E., KRIEGER, H., BABB, L. I., LEVEY, S., and HOLDEN, W. D. (1954), Ann. Surg., 138, 434.

ALBRIGHT, F. (1942), Proc. of the First Conference on Bone and Wound Healing, New York, N.Y., p. 9 ; New York, Josiah,
Macy, jr., Foundation.

BARRTER, F. C. (1956), Metabolism, 5, 369.

BLIXENKRONE-MOLLER, N. (1949), Acta chir. scand., 97, 300. $\vec{\omega}$ CAMPBELL, R. N., CAIRNIE, A. B., POLLAK, J. D. and? CUTHBERTSON, D. P. (I957), Proc. Scot. Soc. exp. Med.O in press.

CLINE, T. M., COLE, J. W., and HOLDEN, W. D. (1953), Surg. Gynec. Obstet., 96, 674.

CUTHBERTSON, D. P. (1929), Biochem. F., $23,1328$.

CUTHBERTSON, D. P. (1930), Ibid., 24, 1244.

CUTHBERTSON, D. P. (1932), Quart. F. Med., 25, 233.

CUTHBERTSON, D. P. (1936), Brit. F. Surg., 23, 505.

CUTHBERTSON, D. P. (1939), Quart. F. exp. Physiol., 29, 13.

DUDLEY, H. A. F., BATCHELOR, A. D. R., and SUTHER LAND, A. B. (1957), Brit. $\mathcal{F}$. plast. Surg.; 9, 275.

DUDLEY, H. A. F., BOLING, E. A., LEQUESNE, L. P., and MOORE, F. D. (1954), Ann. Surg., 140, 354 .

ELKINTON, J. R. (1956), Circulation, 14, 1627 .

FLEAR, C. T. G., and CLARKE, R. (1955), Clin. Sci., 14, 575.

GAMBLE, J. L. (1954), 'Chemical Anatomy, Physiology and Pathology of Extracellular Fluid,' 6th edition, Londer, HARDY, J. D. (1954), 'Surgical Physiology of the Adrenal Corte\&,' HARDY, J. D., and COLE, F. H. (1953), in 'Surgical Foruti , c
p. 536, Philadelphia, W. B. Saunders Co.

HARRIS, G. W. (1955), ' Neural Control of the Pituitary Gland London, Edward Arnold.

HOWARD, J. M. (1955), Ann. Surg., 141, 321.

HUME, D. M. (1953), Ibid., 138, 548.

INGLE, D. J. (1952), F. Endocrin., 8, xxiii.

JEPSON, R. P., JORDAN, A., LEVELL, H. J., and WILSON, G. M. (1957), Ann. Surg., 145, I.

LEQUESNE, L. P., and LEWIS, A. A. G. (1953), Lancet, i, 153.

LEWIS, A. A. G. (1953), Ann. R. Coll. Surg. Engl., 13, 36.

LLAURADO, J. G. (1956), Clin. chim. Acta, 1, 236.

MCCANCE, R. A., and YOUNG, J. (1944), f. Physiol. 102, 41 5 .

MASON, A. S. (1955), Lancet, ii, 632.

MOORE, F. D. (1954), Ұ. Amer. med. Ass., 154, 379.

MOORE, F. D. (1955), Ann. Surg., 141, 141.

MOORE, F. D., and BALL, M. R. (1952), 'The Metabolic $\frac{\overline{3}}{3}$ MOORE, F. D., STEENBURG, R. W., BALL, M. R., WILSON, G. M., and MYRLEN, J. A. (1955), Ann. Surg., 141, 145.

RANDALL, H. T., HABIF, D. V., LOCKWOOD, G. S., and WERNER, S. C. (1949), Surgery, 26, 34I. REISS, E., PEARSON, E., and ARTZ, C. P. (1956), f. clin.
Invest., 35, 62.

ROBSON, J. S., DUDLEY, H. A. F., HORN, D. B., and음 STEWART, C. P. (1955), Lancet, i, 325.
HON, D. B., and ROBSON, J. S., DUDLEY, H. A. F., HORN, D. B., and
STEWART, C. (r956), Clin. chim. Acta, I, 533.
SANDBERG, A. A., EIKNES, I. L., SAMORS, L. T., and

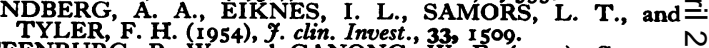
STEENBURG, R. W., and GANONG, W. F. (1955), Surgery,

STEENBURG, R. W., LENNIHAN, R., and MOORE, F. D. N (1956), Ann. Surg., 143, 180.

SUTHERLAND, A. B. (1954), Brit. F. plast. Surg., 8, 68.

VERNEY, E. B. (1947), Proc. roy. Soc. B., 135, 25.

WILKINSON, A. W.'(1956), Lancet, il, 429. NAGY, G., and STEWART, C. P. (r949), Ibid., il, 640. STEWART, C. P. (r950), Ibid., i, 315. H., NAGY, G., and $\mathbb{\mathscr { D }}$ WILSON, G. M., EDELMAN, I.S.' BROOKS, L., MYRDEN,
J. A., HARKEN, D. E., and MOORE, F. D. (1954), Circulation,
9, 199. 9, 199. 